Peter Baeckert, Ursula Ackermann-Liebrich, Gabriel Duc

Klinik für Neonatologie, Universitätsspital, Zürich

\title{
Respiratory distress syndrome in Switzerland: Comparison of the 1984 with the 1974 data
}

In a retrospective study (questionnaire) covering all the neonatal special care units of Switzerland, information was obtained on the problem cases in $87 \%$ of all babies born in $1984^{1} .8 .3 \%$ were hospitalized. Clinical respiratory distress syndrome (RDS) was diagnosed in $31 \%$ of these infants and hyaline membrane disease (HMD) in $6.3 \%$. Mortality in clinical RDS was $7.1 \%$ and in HMD $19 \%$. Mortality showed a high degree of correlation with birthweight. Comparison of the 1984 data with a similar study in $1974^{2}$ showed no significant change in the incidence of clinical RDS. The incidence of HMD (diagnosis by the same criteria) has fallen from $10.1 \%$ to $6.3 \%$. Overall mortality in hospitalized newborns in Switzerland has decreased from $8.8 \%$ in 1974 to $4 \%$ in 1984.

\section{References}

1 Baeckert P, Ackermann-Liebrich U, Duc G. Das neonatale Atemnotsyndrom in der Schweiz. Schweiz. med. Wschr. 1987; 117:1021 - 1027.

2 Fanconi A, Stoll W, Duc G, Bossi E, Prod'hom $S$. Das Atemnotsyndrom des Neugeborenen in der Schweiz. Schweiz. med. Wschr. 1976; 106: $1426-1429$. 